\title{
Frequency Dependence of Impedance of Adhesive Joints
}

\author{
Pavel Mach, Václav Papež, Aleš Duraj \\ Czech Technical University in Prague, Faculty of Electrical Engineering \\ Technická 2, 16627 Prague 2, Czech Republic \\ E-mail: mach@fel.cvut.cz,, Phone: ++420224352122
}

\begin{abstract}
Electrically conductive adhesives have, in comparison with solders, significantly higher non-homogeneity of the structure, and therefore stability of electrical as well as mechanical properties of adhesive joints is lower than soldered ones. The impedance of the joints has been measured in wide frequency range (20 $\mathrm{Hz}$ tol $\mathrm{MHz}$ and $300 \mathrm{MHz}$ to $3 \mathrm{GHz}$. Measurements have been carried out by two methods: impedance in the range $20 \mathrm{~Hz}$ to $1 \mathrm{MHz}$ has been measured by LCR meter HP 4284A. A special test board for assembly of 1 jumper (of the type 1206) by electrically conductive adhesive has been fabricated for this measurement. The measurements at the frequencies $300 \mathrm{MHz}$ and higher have been carried out using a shielded high-Q triplate line.

Specimens have been prepared on Teflon boards, a scalar analyzer Rohde Scwartz ESPI has been used for evaluation. Very low changes of impedances of the joints have been found in the range of $20 \mathrm{~Hz}$ to $1 \mathrm{MHz}$. Typical courses of real and imaginary components of joints impedances in the frequency range $300 \mathrm{MHz}$ to $3 \mathrm{GHz}$ are as follows: the real components have grown in consequence of a skin-effect and have dominated. The imaginary components have been very low. The task for the future research is to explain decrease of the resistance of the joints with growing frequency for two types of adhesives.
\end{abstract}

\section{Introduction}

Soldering processes based on $\mathrm{Sn}-\mathrm{Pb}$ solders are currently under threat from the WEEE (Waste Electrical and Electronic Equipment) and RoHS (Restriction of Hazardous Substances) directives [1]. Different alternatives of these processes are investigated. There are two possible ways how to substitute environmentally dangerous soldering by the use of $\mathrm{Sn}-\mathrm{Pb}$ solders: lead-free soldering or adhesive joining.

Electrically conductive adhesives (ECA) are highly promising materials. They consist of polymer binder and conductive filler. Different types of resins are used for binder, e.g. epoxy resin or silicone resin. Conductive filler consists of metal particles, usually balls with diameter of $6-8$ microns or flakes with dimensions of $6-20$ microns are used. Material of filler is usually silver, but other materials such as $\mathrm{Ni}, \mathrm{Cu}$ covered by $\mathrm{Ag}$ film, $\mathrm{Au}$ or Pd have also been tested successfully. The practical use of some of these materials is limited by their high prices. Also polymer balls covered by thin conductive film, usually silver film, seem to be a good alternative to traditional metal particles.

Adhesives have several advantages compared to traditional soldering technologies. The use of ECAs instead of soldering is more environmentally friendly because adhesive joints are lead-free and do not require fluxes and flux cleaning. Adhesives are cured at lower temperatures than required for soldering and some types of adhesives do not require elevated temperature for curing, they are cured at the normal temperature. Therefore adhesive joining is less destructive for thermally sensitive components than soldering [2].

\section{Basic Properties of Electrically Conductive Adhesives}

Adhesive joining can also be used on non-solderable substrates and the joints with the good conductivity can be created also on the substrates, which are not perfectly cleaned [3].

Solders are always isotropically conductive materials, because solders are different types of metal alloys. Electrically conductive adhesives are of two basic types: adhesives with isotropic electrical conductivity (ICA) and adhesives with anisotropic electrical conductivity (ACA) [4]. Anisotropic adhesives have lower concentration of conductive particles and the joint creates at the higher temperature under mechanical pressure. Because the electrical conductivity of these joints is very good in the direction, which is perpendicular to the board and near to zero in other directions, these adhesive are also know as $\mathrm{z}$-axis adhesives.

The use of ACA continuously grows. They are offered also as foils, which make possible joining of components with higher number of contacts with high effectiveness. 
Electrical properties of adhesive joints are, in comparison with the properties of soldered joints, worse. The contact electrical resistance is higher, and with respect to the structure of conductive adhesives and solders, noise and nonlinearity of adhesive joints are also higher [3][5][6]. The resistivity of adhesive joints to the static and dynamic mechanical loads is lower than the resistivity of soldered joints [1], [7], [8]. Adhesive joints, which has been aged at the higher temperature (e.g. $120{ }^{\circ} \mathrm{C}, 1000$ hours), change their electrical and mechanical properties slightly only. Humidity has significant influence on the properties of the joints. The joints aged at the relative humidity near $100 \%$ for 1000 hours have changed significantly their resistances and nonlinearity. Influence of combined climatic conditions $\left(80^{\circ} \mathrm{C}\right.$, $80 \% \mathrm{RH}, 1000$ hours) on electrical properties of the joints is higher in comparison with the influence of the higher temperature, but significantly lower in comparison with the influence of high humidity [9].

It has been also found that adhesive joints can change their properties if they are loaded by DC current of higher intensity or by current pulses [10]. It is assumed that the current can cause migration of silver ions among conductive particles. Due to this migration some properties of the barriers can be changed. Migration of silver ions out of the joints to create a bridge between neighboring joints separated by a very narrow gaps has not been observed.

Description of a conductivity of a heterogeneous system is complicated by effects on surfaces of heterogeneities, which influence transmission and movement of carriers. Surface of a conductive particle is an area, where traps for carriers exist. Crossing of an electron from one conductive particle to another is influenced by an output work of the material of the matrix. Crossing is possible by different types of mechanisms, e. g. by thermoemission. In this case the level of the current, which passes through the barrier, is described by a Dushman-Richardson equation:

$$
I=A(l-r) T^{2} \exp \left(-\frac{\phi}{k T}\right)
$$

$$
A=4 \pi e m k^{2} / h^{3}
$$

Here $\mathrm{r}$ - coefficient of reflection, $\phi$ - output work, T - temperature, $\mathrm{k}$ - Boltzman constant, $\mathrm{e}$ - charge of electron, $\mathrm{m}-$ mass of electron, $\mathrm{h}-$ Planck constant.
If the intensity of the electrical field is sufficiently high and the barriers among conductive particles very thin, tunneling of electron between neighboring particles can appear. Probability of tunneling of electrons through a barrier with the electrical potential $V_{0}$ and width $a$ is given by the equation

$$
T=\frac{1}{1+\frac{V_{0}^{2} \sinh ^{2} \alpha \cdot a}{4 E\left(e V_{0}-E\right)}} \quad \text { for } E<e V_{0}
$$

Where

$$
\alpha=\left[\frac{2 m\left(e V_{0}-E\right)}{\hbar^{2}}\right]^{1 / 2}
$$

$\mathrm{T}$... coefficient of transmission of a particle with the energy $\mathrm{E}$ through the potential barrier. It follows from the equation (3) that the tunneling current does not depend on the temperature. However, the experiment in real conditions will be influenced by thermal dilatation of the binder and filler.

It can be found from equations (1) and (3) that the conductivity of electrically conductive adhesives will be nonlinear in principle.

\section{Methods for the Measurement of the Impedance of the Joints}

The measurement of impedances of adhesive joints is limited on the measurement of their resistances usually, because imaginary parts of impedances are very low in comparison with the real one. Value of the impedance of an adhesive joint is usually 5 to $15 \mathrm{~m} \Omega$ for a contact of a 1206 resistor at the low frequency.

If the resistance of an adhesive joint is measured in at low frequencies, a four point method must be used to avoid errors caused by contact resistances.

The measurement of impedance at lower frequency range, $20 \mathrm{~Hz}$ to $1 \mathrm{MHz}$, is very simple. It has been carried out using an RLC meter HP 4284A. The specimen consists of the resistor with "zero" resistance (jumper) mounted on proper pads using electrically conductive adhesive. To minimize errors caused by conductive connections between the specimen and measuring equipment, these connections must be as short as possible. Therefore a special fixture with one jumper and two adhesive joints has been made. It has been clapped directly on connectors of the RLC meter.

The measurement of impedances of the joints at the high frequency range, $200 \mathrm{MHz}$ to $3 \mathrm{GHz}$, is more difficult. The "high-Q" triplate stripline has 
been used for this measurement [11]. The cross section of this type of the resonator is shown in Fig. 1.

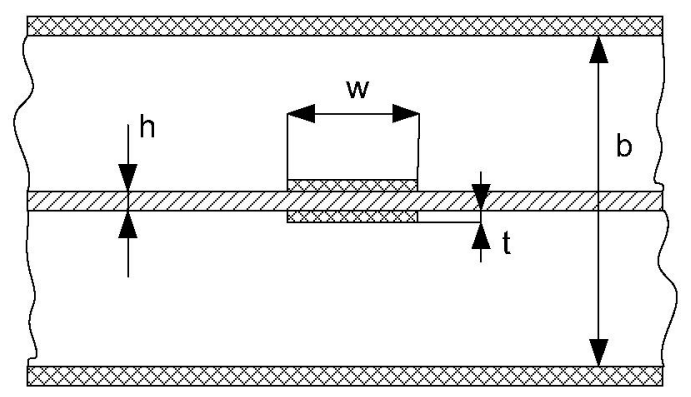

Fig. 1 Structure of a High-Q triplate stripline

The methodology of the measurement is based on utilization of a resonator with the stripline of the type TEM for the measurement of small impedances. The resonator is designed as at the ends opened resonator of the length $(2 n-1) \lambda / 2$ with nonsymmetrical stripline. In the middle of the stripline, where it is located the maximum of the resonant current, is a live conductor interrupted and the gap is bridged by the measured impedance. This bridge is joined with the line using electrically conductive adhesive. The electrical contact resistance is evaluated as the real part of impedance by the use of a following way: the Q-factor of the resonator with the adhesive joints and of the Q-factor of the resonator with the joints carried out by soldering (it has been found that the soldered joints have $10 \mathrm{x}$ to $100 \mathrm{x}$ lower resistance in comparison with the adhesive ones) are mutually compared.

\section{Analysis of a measuring method}

A symmetrical resonator with the length of $n \lambda / 2$ (see Fig. 2a)

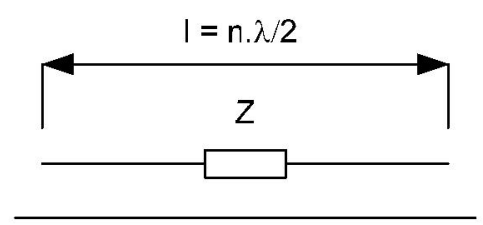

Fig. 2a Symmetrical resonator

has been simplified for following analysis on its one half as a $\lambda / 4$ opened resonator of the length $(2 n-1) . \lambda / 4$ with defined impedance of a shorted link (Z/2) - see Fig. $2 b$.

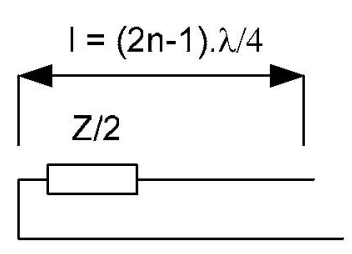

Fig. 2b Simplification for following analysis

The Q-factor of the resonator can be expressed by the use of generalized definition of the Q-factor on the basis of the ratio of total energy accumulated in the electromagnetic field of the resonator and the power losses in the resonator [11]:

$$
Q=\frac{\omega W_{a}}{P}
$$

It can be written for the power losses if Q-factor of the resonator with the minimum resistance is $\mathrm{Q}_{0}$ and the resonator with the measured resistance has the $\mathrm{Q}$-factor $\mathrm{Q}_{\mathrm{M}}$, and if the frequency would be changed slightly only:

$$
\frac{1}{Q_{0}}=\frac{P_{0}}{\omega W_{a}}
$$

$$
\frac{1}{Q_{M}}=\frac{P_{0}+P_{M}}{\omega W_{a}}
$$

Where $\mathrm{P}_{0}$ is the power lost in the resonator out of the specimen, $P_{M}$ is the power lost in the specimen.

The power lost in the specimen can be expressed using the formula:

$$
\frac{1}{Q_{M}}-\frac{1}{Q_{0}}=\frac{P_{M}}{\omega W_{a}}
$$

The power lost in the real part $R_{1}$ of the impedance $Z / 2$ can be written in dependence on the maximum voltage $U_{\max }$ in the resonator and the characteristic impedance $Z_{0}$ of the stripline:

$$
P_{M}=\frac{R_{1}}{2 Z_{0}} U_{M A X}^{2}
$$

Energy of the electromagnetic field in the resonator at the resonance can be expressed using the equation:

$$
W_{A}=\frac{1}{4} \frac{l_{1}}{v} \frac{U_{M A X}^{2}}{Z_{0}}
$$


Where $l_{1}$ is the length of the resonator $(2 n-1) \cdot \lambda / 4$, $v$ is the phase velocity in the resonator.

After substitution of (9) and (10) into (8) it will be found:

$$
\frac{1}{Q_{M}}-\frac{1}{Q_{0}}=\frac{R_{1}}{Z_{0}} \frac{v}{\pi l_{1} f}
$$

The resistance of the shorted link in the $\lambda / 4$ resonator can be calculated as follows:

$$
R_{1}=\left(\frac{1}{Q_{M}}-\frac{1}{Q_{0}}\right) \frac{Z_{0} \pi d_{1}}{\lambda}
$$

After re-calculation for the resonator of doubled length the final formula for the calculation of the resistance $R=2 R_{1}$ of the specimen is found:

$$
R=\left(\frac{1}{Q_{M}}-\frac{1}{Q_{0}}\right) \frac{Z_{0} \pi m}{2}
$$

Where $\mathrm{m}$ is the length of the resonator:

$$
l=m \cdot \frac{\lambda}{2}
$$

\section{Measuring equipment}

The measuring fixture has been made with stripline Shielded high-Q triplate line with the impedance $Z 0=50 \Omega$ [12]. The inner conductor has been made on a PTFE (Taconic TLY 5A-C1) of the thickness $0,78 \mathrm{~mm}$ with $\mathrm{Cu}$ cladding $35 \mu \mathrm{m}$, the external conductor has been, with respect to the maximum mechanical stability of the fixture, milled of $\mathrm{Cu}$ bands.

The resonator has been as a two-port network connected to a scalar analyzer Rohde-Schwartz ESPI (see Fig. 3). Couplings on output striplines have been chosen very weak, transmission of the resonator in resonance has been about minus $40 \mathrm{~dB}$. The Q-factor of the resonator without the specimen has been approximately 300 at the frequency of 300 $\mathrm{MHz}$ and approximately 600 for the frequency of 3 $\mathrm{GHz}$. Resolution of this equipment for the measurement of the impedance has been about $2 \mathrm{~m} \Omega$. The impedances have been measured in the frequency range $300 \mathrm{MHz}$ to $3 \mathrm{GHz}$.

\section{Results of the measurement}

Seven types of adhesives of the company Amepox have been tested: 55MN, 55MNa, AX70N, ER48, ER48a, AX20, AX20a. All these adhesives

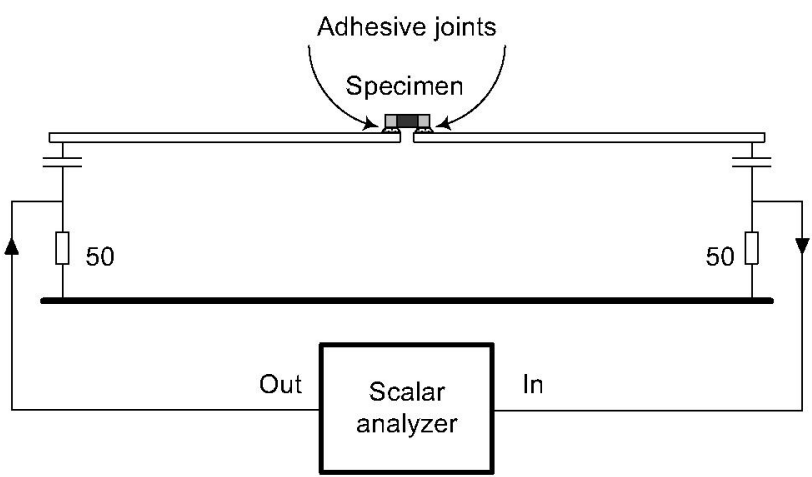

Fig. 3 Arrangement of the measurement

are one-part adhesives with isotropic electrical conductivity and with epoxy matrix and silver filler.

Typical courses of the impedances of adhesive joints in the frequency range $20 \mathrm{~Hz}$ to $1 \mathrm{MHz}$ are shown in Fig. 4.

It has been found that the changes of the impedances of the joints are very low in this frequency range, imaginary parts of the impedances

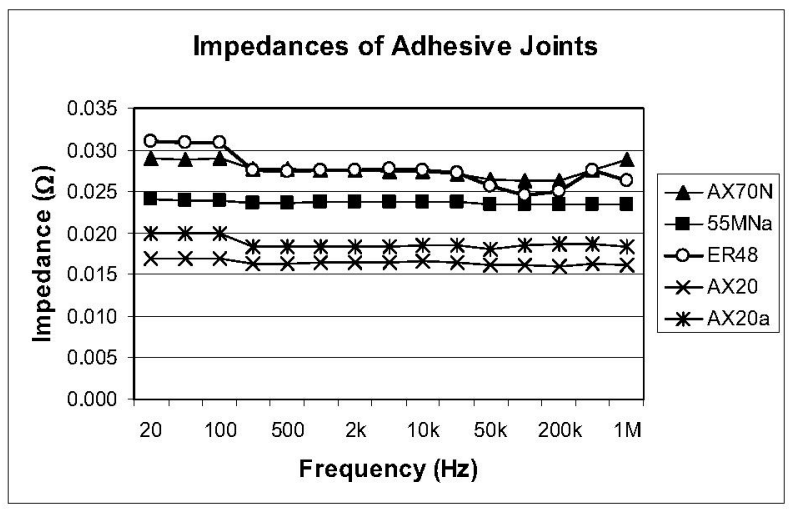

Fig. 4 Impedances of adhesive joints in the frequency range $20 \mathrm{~Hz}$ to $1 \mathrm{MHz}$

are negligible in comparison with the resistances of the joints, and therefore the impedances are approximately equal to the resistances of the joints (there are shown courses of the impedances of the joints fabricated of 5 types of adhesives in Fig. 4. Total number of types of adhesives under test has been 7 . The courses of the impedances fabricated of adhesives of 2 types, which are not presented, have been of the same type. They are not drawn in the figure to improve its readability).

The measurements in the frequency range of $300 \mathrm{MHz}$ to $3 \mathrm{GHz}$ have been carried out using the high-Q triplate stripline. The impedances of the joints have been calculated as follows: 
- The standard specimen has been fabricated at first. The standard has been carried out by mounting of the jumper of the same type on the test board using soldering. Considering the fact that the soldered joints have substantially lower impedances in comparison with adhesive ones, the impedance of the soldered jumper has been taken as a standard.

- The impedance of the jumper mounted using electrically conductive adhesive has been measured at different frequencies and at the same frequencies the impedance of the standard has been measured. The impedances of the adhesive joints have been calculated as follows:

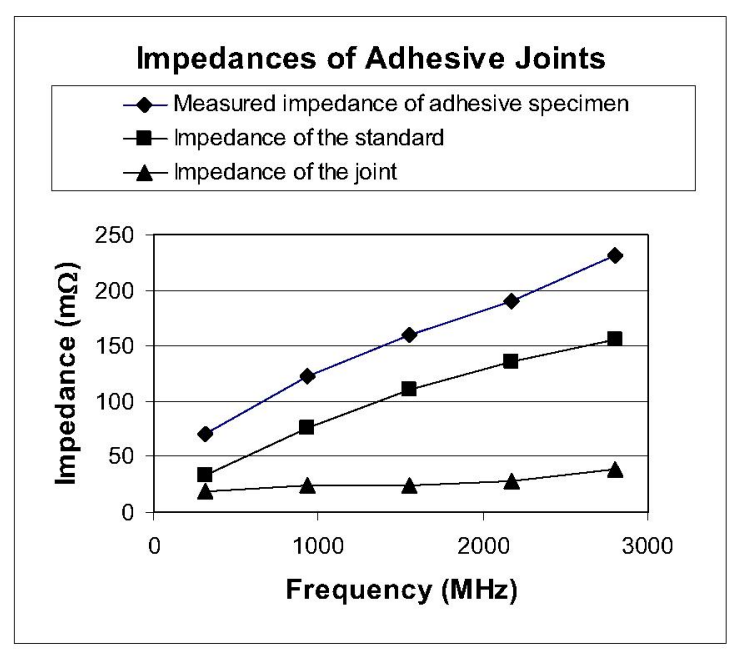

Fig. 5 Principle of calculation of the joints impedances

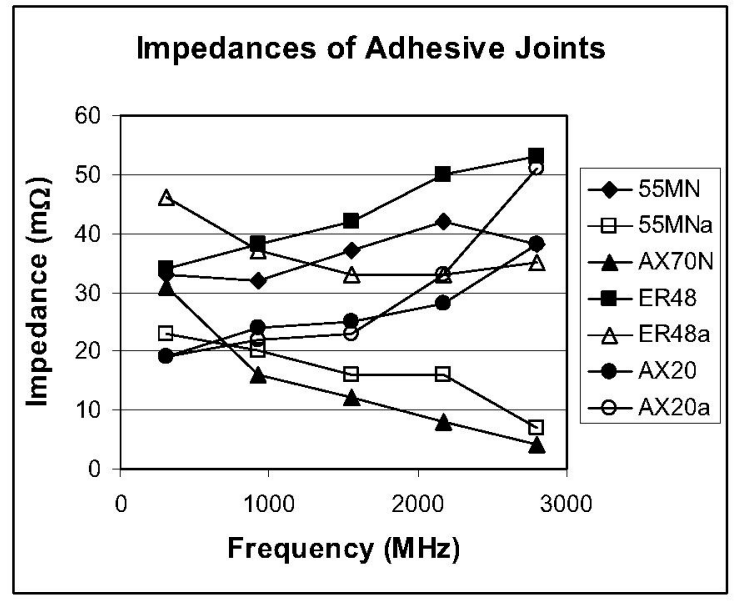

Fig. 6 Impedances of adhesive joints made of different types of electrically conductive adhesives

$$
Z_{1}=\frac{Z_{T O T}-Z_{S T}}{2}
$$

Where $Z_{1} \ldots$ impedance of an adhesive joint, $\mathrm{Z}_{\mathrm{TOT}}$ ... impedance of the jumper mounted by adhesive (impedance of the jumper $+2 \mathrm{x}$ impedance of the adhesive joint), $Z_{\mathrm{SR}} \ldots$ impedance of the standard. It has been found that the imaginary part of the impedance is very low and therefore it can be neglected. Therefore it is possible to write:

$$
Z_{1} \approx R_{1}
$$

The process of ascertaining of the joint impedance is shown in Fig. 5.

The frequency dependences of the impedances of the joints made of different types of adhesives are shown in Fig. 6.

\section{Discussion of Results}

It has been found that the frequency dependence of the adhesive joints is weak. With respect to the very low imaginary part of the impedance it is assumed that the growth of the impedances with growing frequency is caused by the skin-effect. The decrease of the impedance with the growing frequency for adhesives AX70N and 55MNa is unexpected. It could be caused by micro-cracks in adhesive joints, by other inhomogeneities, or by other reasons. Explanation of this decrease will be the goal of our future work in this field.

\section{Conclusions}

The frequency dependence of impedances of adhesive joints has been investigated in two frequency ranges: $20 \mathrm{~Hz}$ to $1 \mathrm{MHz}$ and $300 \mathrm{MHz}$ to $3 \mathrm{GHz}$. The imaginary parts of the impedances of the joints are very low in comparison with their real parts. Therefore the values of the impedances are approximately of the same value like the values of the resistances of the joints. It has been also found that the impedances of the joints do not change in the frequency range $20 \mathrm{~Hz}$ to $1 \mathrm{MHz}$. In the frequency range $300 \mathrm{MHz}$ to $1 \mathrm{GHz}$ the impedances mostly grow. The increase of the values of the impedances is caused by the skin-effect. It has also been found that the impedances of the joints made of two types of adhesives have decreased with growing frequency. It is assumed that the reason of such the course could be inhomogeneities in the material, but this assumption must be attested by following experiments.

It has been also found that the high-Q triplate stripline can be used for such the measurement, because it has sufficient sensitivity. 


\section{Acknowledgments}

The work has been carried out with the financial support of the project "Diagnostics of Materials", MSM 6840770021.

\section{References}

1. Website on the Implementation of the EU Directives on Waste Electrical and Electronic Equipment (WEEE), and on the - Restriction on Hazardous Substances(RoHS),

http://www.environ.ie/DOEI/DOEIPol.nsf/wvNavVie w/Waste+Electrical+\&+Electronic+Equipment?Open Document\&Lang=

2. Keil, M. et al., "Isotropic conductive adhesive joints", Advanced Packaging, September, 2001, http://ap.pennnet.com/Articles/Article_Display.cfm?S ection=Articles\&Subsecti\%3Cbr\%3Eon=Display\&A RTICLE_ID $=115437$

3. Mach, P., Bušek, D., Duraj, D., "Stability of Adhesive Joints Created on Pads with Different Types of Surfaces Finishes", Proc. SIITME 2005, ClujNapoca, Sept. 2005, pp. $20-24$

4. Lau, J. H., Wong, C. P., Lee, N. C. Lee, W. R., Electronics Manufacturing with Lead-Free, HalogenFree \& Conductive -Adhesive materials, McGrawHill, (N.Y. 2004)

5. Vávra, R., Mach, P., "Quality of Adhezive Joints, Joints Realized by Lead Free Solders and $\mathrm{Sn}-\mathrm{Pb}$ Solder During Accelerated Stress Test", Proc. ISSE 2002, Prague, Czech Rep., Mai 2002, Vol. 1, pp. 334341

6. Duraj, A., Mach, P., Vávra, R., "Electrically conductive adhesives versus Lead-free Solders" Proc. European Microelectronics and Packaging Symposium, Prague, Czech Rep., June 2004, pp. 541 546

7. Mach, P., "Properties of Adhesive Bonds Exposed to the Static and Dynamic Mechanical Load", Proc. 26th International Spring Seminar on Electronics Technology. Košice, Slovakia. Mai 2003, pp. 412-416

8. Mach, P., Krejzlik, V., "Properties of Electrically conductive adhesive joints under mechanical load", SIITME 02 - 8th International Symposium for Design and Technology of Electronic Modules, Bucharest, Romania, September 2002, Vol. 1, pp. 5-9

9. Mach, P., DURAJ, A., Bušek, D., Ješ, J., Orth, T., „Diagnostics of adhesive bonds”, Proc. European Microelectronics and Packaging Symposium, Prague, Czech Rep., June 16 to 18, 2004, pp. $83-88$

10. Mach, P., Ješ, J., Papež, V., "Degradation of Adhesive Bonds with Short Current Pulses", Proc. 26th International Spring Seminar on Electronics Technology. Košice, Slovakia, 2003, pp. 339-343.

11. Gunston, M. A. R.: Microwave Transmission-Line Impedance Data, Van Nostrand Reinhold Company, (N. Y. 1986), pp. 55 - 62
12. Kummer, M.: Grundlagen der Mikrowellen Technik. (in German), VEB Verlag Technik (Berlin, 1989), pp. $100-108$ 